\title{
A Model for Predicting Concentrations of Carbon Monoxide in Building Fires
}

\author{
SHIGERU YAMADA \\ Technical Research Institute, Fujita Corporation \\ 74 Ohdana-chou Kouhoku-ku, Yokohama, Kanagawa, 223 Japan
}

TAKEYOSHI TANAKA

Building Research Institute, Ministry of Construction

1 Tatehara, Tsukuba, Ibaraki, 305 Japan

\section{ABSTRACT}

Several experiments conducted to date suggest that yield of carbon monoxide is strongly affected by 'equivalence ratio'. So it seems worthwhile to develop an empirical model of $\mathrm{CO}$ yields as a function of equivalence ratio, and to use this model as the source term in fire models for the prediction of CO concentrations in building fires. In the preceding paper, we presented a theoretical model for predicting the yields of chemical species for propane fire.

In this paper, we extend the model to generic fuel, and incorporate the model into BRI2 fire mode1 and attempt to predict the concentrations of $\mathrm{C} 0$ in transient fire. Also the predictions are compared with the results of the reduced scale single fire tests. Some discrepancies between the predicted and experimental values still remain, however, this methodology seems to be a convenient and viable way of predicting $C O$ yields in transient state.

KEYWORDS : fire modeling, carbon monoxide, equivalence ratio, normalized yield

\section{INTRODUCTION}

The ultimate goal of this study is to develop a practical means to predict the concentrations of carbon monoxide ( $\mathrm{CO}$ ) contained in fire effluents in the event of building fires. In the preceding paper[1], we presented a model for predicting the yields of chemical species for propane fire, in which the yields of a certain number of incomplete combustion products, in addition to the products of complete combustion, which are the same as shown in Figure 1, are assumed. The equations for the normalized yield of each species and the concentration of the species in the layer containing the combustion products in two layer configuration were derived as a function of the parameters introduced in the combustion mode1. The values of parameters were determined as such that the normalized yields and the 
layer concentrations of the chemical species theoretically derived best agree with Beyler's test data[2].

In this paper we extend the model from propane fuel to generic fuel, and we incorporate the model into BRI2 fire model and attempt to predict the concentrations of $\mathrm{CO}$ in transient fire. Also the predictions are compared with the results of the reduced scale single fire tests.

The influence of temperature on species yields has been reported [3], but is ignored in this paper.

\section{THE MODEL FOR THE YIELDS OF CHEMICAL SPECIES FOR GENERIC FUELS}

\subsection{Equivalence Ratio}

We assume that air is composed solely of $\mathrm{O}_{2}$ and $\mathrm{N}_{2}$, ignoring the other chemical species because of their small fractions. Fuel is assumed to be composed of carbon, hydrogen, oxygen and nitrogen. The chemical equation of the complete combustion can be expressed as :

$$
\nu_{2}{ }^{\prime}[\mathrm{F}]+\nu_{\mathrm{O}_{2}}{ }^{\prime}\left[\mathrm{O}_{2}\right]+\nu_{\mathrm{N}_{2}}{ }^{\prime}\left[\mathrm{N}_{2}\right] \rightarrow \nu_{\mathrm{CO}_{2}}{ }^{\prime}\left[\mathrm{CO}_{2}\right]+\nu_{\mathrm{H} 2 \mathrm{O}^{\prime \prime}}\left[\mathrm{H}_{2} \mathrm{O}\right]+\nu_{\mathrm{N}_{2}}{ }^{\prime \prime}\left[\mathrm{N}_{2}\right]
$$

The rates of production of an arbitrary species $\ell$ in this reaction can be expressed as :

$$
W_{\ell}=\frac{\left(\nu \ell^{\prime \prime}-\nu_{\ell}{ }^{\prime}\right) M_{\ell}}{\nu_{t} M_{l}}
$$

Using Eq. (2), stoichiometric fuel/air ratio $\Phi_{s}$ becomes as follows :

$$
\Phi_{\mathrm{S}} \equiv \frac{W_{\mathrm{f}}}{W_{\mathrm{a}}}=\frac{-\mathrm{m}_{\mathrm{f}}}{-\frac{1}{\mathrm{Y}_{02}{ }^{\mathrm{a}}} \cdot \frac{\nu_{02} \mathrm{M}_{02}}{\nu_{\mathrm{f}} \mathrm{M}_{\mathrm{f}}} \mathrm{m}_{\mathrm{f}}}=\mathrm{Y}_{02}{ }^{\mathrm{a}}\left(\frac{\nu_{\mathrm{f}} \mathrm{M}_{\mathrm{f}}}{\nu_{02} \mathrm{M}_{02}}\right)
$$

On the other hand, the fuel/air ratio of combustion under an arbitrary condition $\Phi_{\mathrm{n}}$ is defined as :

$\Phi_{a} \equiv \frac{m_{f}}{m_{a}}$

From Eqs. (3) and (4), the equivalence ratio, in other words, normalized fuel/air ratio $\Phi$ becomes as follows :

$\Phi \equiv \frac{\Phi_{a}}{\Phi_{S}}=\frac{m_{f} / m_{a}}{Y_{02}{ }^{a}\left(\nu_{f}^{\prime} M_{f} / \nu_{02} \cdot M_{02}\right)}$

\subsection{Burning Rate of Fuel}

It is assumed that the burning rate of fuel is determined by the smaller of the fuel inputs (volatile generation rate due to thermal decomposition in case of solid fuel) and the rate of fuel that can be burned by the available air. More specifically, the burning rate $m_{b}$ is given as follows :

a) when $\Phi \leqq 1$ (fuel lean case)

$m_{b}=m_{e}$

b) when $\Phi>1$ (fuel rich case)

$m_{b}=\frac{\nu_{e}^{\prime} M_{f}}{\nu_{02}^{\prime} M_{02}} m_{02}=Y_{02}{ }^{a}\left(\frac{\nu_{e}^{\prime} M_{f}}{\nu_{02}^{\prime} M_{02}}\right) m_{a}=\frac{m_{t}}{\Phi}$ 


\section{3 Mole Numbers of Combustible Materials}

In general, the fuel in actual fires are much more complex than the fuels for which the species yields are being investigated experimentally. For such materials as woods and polymers, the chemical formulas are not always known, but the mass fractions of each element is usually available. [4,5]

Letting $X_{C}, X_{H}, X_{O}$ and $X_{N}$ be the mass fractions of carbon, hydrogen, oxygen and nitrogen in the fuel, respectively, and $z$ be the fraction of residual char (i.e. carbon), the mole number of each element in unit mass of the volatile leaving the fuel can be calculated as :

$\nu_{c}=\frac{X_{\mathrm{C}}-\mathrm{Z}}{12(1-\mathrm{z})} \times 10^{3}, \quad \nu_{\mathrm{H}}=\frac{\mathrm{X}_{\mathrm{H}}}{1-\mathrm{z}} \times 10^{3}, \quad \nu_{O}=\frac{\mathrm{X}_{\mathrm{O}}}{16(1-\mathrm{z})} \times 10^{3}, \quad \nu_{\mathrm{N}}=\frac{\mathrm{X}_{\mathrm{N}}}{14(1-\mathrm{z})} \times 10^{3}$

\section{4 The Combustion Model and The Chemical Equation}

The combustion model is shown in Figure 1, and the chemical equation for this model is expressed as follows :

$$
\begin{aligned}
\mathrm{C} \nu_{\mathrm{CH}} \nu_{\mathrm{H}} \mathrm{O} \nu_{\mathrm{ON}} \nu_{\mathrm{N}} & +\left(\nu_{\mathrm{C}}+\frac{\nu_{\mathrm{H}}}{4}-\frac{\nu_{\mathrm{O}}}{2}\right] \mathrm{O}_{2} \\
& \rightarrow(1-\mathrm{r}) \mathrm{s}\left[\mathrm{C} \nu_{\mathrm{CH}} \nu_{\mathrm{H}} \mathrm{O} \nu_{\mathrm{ON}} \nu_{\mathrm{N}}\right] \\
& +(1-\mathrm{r})\left[\left\{1-(1-\mathrm{s})\left(1-\frac{\mathrm{p}_{1}}{2}-\mathrm{p}_{2}\right)\right\} \nu_{\mathrm{C}}+\left\{1-(1-\mathrm{s})\left(1-\mathrm{q}_{1}\right)\right\} \frac{\nu_{\mathrm{H}}}{4}-\mathrm{s} \frac{\nu_{\mathrm{O}}}{2}\right]\left[0_{2}\right] \\
& +\left\{\mathrm{r}+(1-\mathrm{r})(1-\mathrm{s})\left(1-\mathrm{p}_{1}-\mathrm{p}_{2}\right)\right\} \nu_{\mathrm{C}}\left[\mathrm{CO}_{2}\right] \\
& +(1-\mathrm{r})(1-\mathrm{s}) \mathrm{p}_{1} \nu_{\mathrm{C}}[\mathrm{CO}] \\
& +(1-\mathrm{r})(1-\mathrm{s}) \mathrm{p}_{2} \nu_{\mathrm{C}}[\mathrm{C}] \\
& +\left\{\mathrm{r}+(1-\mathrm{r})(1-\mathrm{s})\left(1-\mathrm{q}_{1}\right)\right\} \frac{\nu_{\mathrm{H}}}{2}\left[\mathrm{H}_{2} \mathrm{O}\right] \\
& +(1-\mathrm{r})(1-\mathrm{s}) \mathrm{q}_{1} \frac{\nu_{\mathrm{H}}}{2}\left[\mathrm{H}_{2}\right] \\
& +\{\mathrm{r}+(1-\mathrm{r})(1-\mathrm{s})\} \frac{\nu_{\mathrm{N}}}{2}\left[\mathrm{~N}_{2}\right]
\end{aligned}
$$

\subsection{Yields of Species}

(1) Rate of production of species

Based on the combustion model described above, the rates of production of species are given by applying Eq. (2) to the chemical Eq. (8) as :

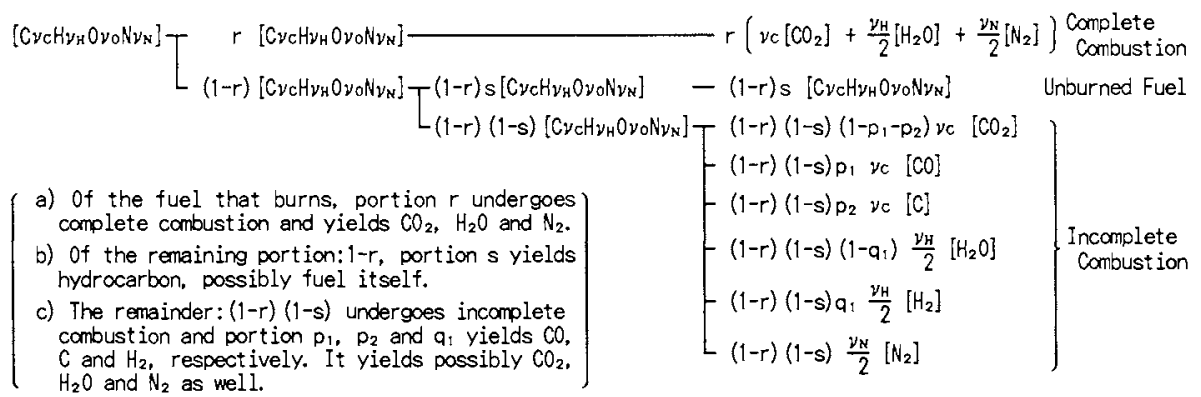

FIGURE 1. Combustion model for generic fuel 
$W_{\mathrm{f}}=-\{1-(1-\mathrm{r}) \mathrm{s}\} \mathrm{m}_{\mathrm{b}}$

$W_{02}=-\left[\left\{r+(1-r)(1-s)\left(1-\frac{p_{1}}{2}-p_{2}\right)\right\} \nu_{c}+\left\{r+(1-r)(1-s)\left(1-q_{1}\right)\right\} \frac{\nu_{H}}{4}-\{1-(1-r) s\} \frac{\nu_{0}}{2}\right] M_{02} m_{b}$

$W_{c 02}=\left\{r+(1-r)(1-s)\left(1-p_{1}-p_{2}\right)\right\} \quad v_{c} M_{c 02} m_{b}$

$W_{c o}=(1-r)(1-s) p_{1} v_{c} M_{c o} m_{b}$

$W_{c}=(1-r)(1-s) p_{2} v_{c} M_{c} m_{b}$

$W_{H 2 O}=\left\{r+(1-r)(1-s)\left(1-q_{1}\right)\right\} \nu_{H} M_{H 2 O} m_{b} / 2$

$W_{\mathrm{H} 2}=(1-r)(1-\mathrm{s}) \mathrm{q}_{\mathrm{i}} \nu_{\mathrm{H}} \mathrm{M}_{\mathrm{H} 2} \mathrm{~m}_{\mathrm{b}} / 2$

$W_{\mathrm{N} 2}=\{r+(1-\mathrm{r})(1-\mathrm{s})\} v_{\mathrm{N}} M_{\mathrm{N} 2} \mathrm{~m}_{\mathrm{b}} / 2$

(2) Normalized yield of species

Normalized yield of species is defined as the ratio of production of a species to the theoretically maximum yield of the species, however, here we use a special definition for fuel for convenience in comparing theoretical predictions with the existing test data, i.e.,

$\bar{W}_{\mathrm{f}}=1-\left(W_{\mathrm{f}} / \mathrm{W}_{\mathrm{f}}^{*}\right)$

where $W_{f}^{*}$ is the theoretically maximum yield of fuel.

Finally, the normalized yield of each species is given as follows :

a) when $\Phi \leqq 1$ (fuel lean case)

$\bar{W}_{f}=(1-r) s$

$\bar{W}_{02}=\left[\left\{r+(1-r)(1-s)\left(1-\frac{p_{1}}{2}-p_{2}\right)\right\} \nu_{c}+\left\{r+(1-r)(1-s)\left(1-q_{1}\right)\right\} \frac{\nu_{H}}{4}-\{1-(1-r) s\} \frac{\nu_{0}}{2}\right]$

$/\left(\nu_{c}+\frac{\nu_{\mathrm{H}}}{4}-\frac{\nu_{0}}{2}\right)$

$\bar{W}_{\mathrm{CO} 2}=r+(1-r)(1-s)\left(1-p_{1}-p_{2}\right)$

$\vec{W}_{c o}=(1-r)(1-s) p_{1}$

$\bar{W}_{\mathrm{C}}=(1-\mathrm{r})(1-\mathrm{s}) \mathrm{p}_{2}$

$\overline{\mathrm{W}}_{\mathrm{H} 2 \mathrm{O}}=\mathrm{r}+(1-\mathrm{r})(1-\mathrm{s})\left(1-\mathrm{q}_{1}\right)$

$\bar{W}_{\mathrm{H} 2}=(1-\mathrm{r})(1-\mathrm{s}) \mathrm{q}_{1}$

$\bar{W}_{\mathrm{N} 2}=r+(1-r)(1-s)$

b) when $\Phi>1$ (fuel rich case)

$$
\begin{aligned}
\bar{W}_{\mathrm{f}}= & 1-\{1-(1-\mathrm{r}) \mathrm{s}\} / \Phi \\
\bar{W}_{\mathrm{O} 2}= & {\left[\left(\mathrm{r}+(1-\mathrm{r})(1-\mathrm{s})\left(1-\frac{\mathrm{p}_{1}}{2}-\mathrm{p}_{2}\right)\right\} \nu_{\mathrm{C}}+\left\{\mathrm{r}+(1-\mathrm{r})(1-\mathrm{s})\left(1-\mathrm{q}_{1}\right)\right\} \frac{\nu_{\mathrm{H}}}{4}-\{1-(1-\mathrm{r}) \mathrm{s}\} \frac{\nu_{0}}{2}\right] \cdot \frac{1}{\Phi} } \\
& /\left(\nu_{\mathrm{C}}+\frac{\nu_{\mathrm{H}}}{4}-\frac{\nu_{0}}{2}\right) \\
\bar{W}_{\mathrm{CO} 2}= & \left\{\mathrm{r}+(1-\mathrm{r})(1-\mathrm{s})\left(1-\mathrm{p}_{1}-\mathrm{p}_{2}\right)\right\} / \Phi \\
\bar{W}_{\mathrm{CO}}= & (1-\mathrm{r})(1-\mathrm{s}) \mathrm{p}_{1} / \Phi \\
\bar{W}_{\mathrm{C}}= & (1-\mathrm{r})(1-\mathrm{s}) \mathrm{p}_{2} / \Phi \\
\bar{W}_{\mathrm{H} 2 \mathrm{O}}= & \left\{\mathrm{r}+(1-\mathrm{r})(1-\mathrm{s})\left(1-\mathrm{q}_{1}\right)\right\} / \Phi \\
\bar{W}_{\mathrm{H} 2}= & (1-\mathrm{r})(1-\mathrm{s}) \mathrm{q}_{1} / \Phi \\
\bar{W}_{\mathrm{N} 2}= & (\mathrm{r}+(1-\mathrm{r})(1-\mathrm{s})\} / \Phi
\end{aligned}
$$

Where use was made of the definition described by Eq. (5) as well as Eq. (6.1), Eq. (6.2) and Eq. (9). 


\subsection{Species Mass Concentration in The Product Layer}

A typical configuration of fire in a space is illustrated in Figure 2. Also, the setups of the existing experiments to investigate the issue of $\mathrm{CO}$ yield may be reduced to similar configuration. In such a case, the concentration of species in the layer at steady state has one-to-one correspondence to equivalence ratio. This correlation is expressed as follows.

(1) Conservation for the product layer

Considering the overall mass and species concentration for steady state, we obtain the following equations :

1) Overall mass balance

$$
m_{e}=m_{s}+m_{a}
$$

2) Species balance

$$
\mathrm{Y}_{\ell} \mathrm{m}_{\mathrm{e}}=\mathrm{Y}_{\ell} \mathrm{m}_{\ell}+\mathrm{Y}_{\ell} \mathrm{m}_{\mathrm{a}}+\mathrm{H}_{\ell}
$$

From Eq. (12) and Eq. (13), the mass fraction of species $\ell$ in the layer $\mathrm{Y}_{\ell}$ becomes

$$
Y_{\ell}=\frac{m_{f}}{m_{a}+m_{l}} Y_{\ell}+\frac{m_{a}}{m_{a}+m_{l}} Y_{\ell}{ }^{a}+\frac{1}{m_{a}+m_{l}} W_{\ell}
$$

Using the fuel/air ratios defined by Eq. (3), Eq. (4) and Eq. (5), this becomes :

$$
\begin{aligned}
Y_{l} & =\frac{\Phi_{a}}{1+\Phi_{a}} Y_{l}{ }^{2}+\frac{1}{1+\Phi_{a}} Y_{l}^{a}+\frac{1}{m_{a}+m_{l}} W_{l} \\
& =\frac{\Phi_{S} \Phi}{1+\Phi_{S} \Phi} Y_{l}+\frac{1}{1+\Phi_{S} \Phi} Y_{l}^{a}+\frac{1}{m_{a}+m_{l}} W_{l}
\end{aligned}
$$

(2) Concentration of each species in the layer

Substituting $W_{\ell}$ in Eq. (9) into Eq. (15) yields the mass fraction of species $\ell$ in the layer. The mass fraction of each species becomes :

a) when $\Phi \leqq 1$ (fuel lean case)

$$
\begin{aligned}
& Y_{P}=\frac{\Phi_{S} \Phi}{1+\Phi_{S} \Phi}(1-r) s \\
& Y_{02}=\left\{1-\left[\left\{r+(1-r)(1-s)\left(1-\frac{p_{1}}{2}-p_{2}\right)\right\} v_{c}+\left\{r+(1-r)(1-s)\left(1-q_{1}\right)\right\} \frac{\nu_{H}}{4}-\{1-(1-r) s\} \frac{\nu_{0}}{2}\right] \frac{\Phi}{v_{02}{ }^{*}}\right] \\
& \cdot Y_{02} /\left(1+\Phi_{S} \Phi\right) \\
& \mathrm{Y}_{\mathrm{CO} 2}=\frac{\Phi_{\mathrm{S}} \Phi}{1+\Phi_{S} \Phi} \cdot\left\{\mathrm{r}+(1-\mathrm{r})(1-\mathrm{s})\left(1-\mathrm{p}_{1}-\mathrm{p}_{2}\right)\right\} \nu_{\mathrm{C}} \mathrm{M}_{\mathrm{CO} 2} \\
& Y_{\mathrm{co}}=\frac{\Phi_{\mathrm{S}} \Phi}{1+\Phi_{\mathrm{S}} \Phi} \cdot(1-r)(1-s) p_{1} v_{c} M_{c o} \\
& \mathrm{Y}_{\mathrm{c}}=\frac{\Phi_{S} \Phi}{1+\Phi_{S} \Phi} \cdot(1-\mathrm{r})(1-\mathrm{s}) \mathrm{p}_{2} v_{\mathrm{c}} M_{\mathrm{c}} \\
& \mathrm{Y}_{\mathrm{H} 2 \mathrm{O}}=\frac{\Phi_{S} \Phi}{1+\Phi_{\mathrm{S}} \Phi} \cdot \frac{\left\{\mathrm{r}+(1-\mathrm{r})(1-\mathrm{s})\left(1-\mathrm{q}_{1}\right)\right\} \nu_{\mathrm{H}} M_{\mathrm{H} 2 \mathrm{O}}}{2} \\
& \mathrm{Y}_{\mathrm{H} 2}=\frac{\Phi_{\mathrm{S}} \Phi}{1+\Phi_{S} \Phi} \cdot \frac{(1-r)(1-s) q_{1} \nu_{\mathrm{H}} M_{\mathrm{H} 2}}{2} \\
& \mathrm{Y}_{\mathrm{N} 2}=\frac{\Phi_{\mathrm{S}} \Phi}{1+\Phi_{\mathrm{S}} \Phi} \cdot \frac{\{\mathrm{r}+(1-\mathrm{r})(1-\mathrm{S})\} \nu_{\mathrm{N}} \mathrm{M}_{\mathrm{N} 2}}{2}+\frac{1-\mathrm{Y}_{\mathrm{o} 2}{ }^{\mathrm{a}}}{1+\Phi_{\mathrm{S}} \Phi}
\end{aligned}
$$

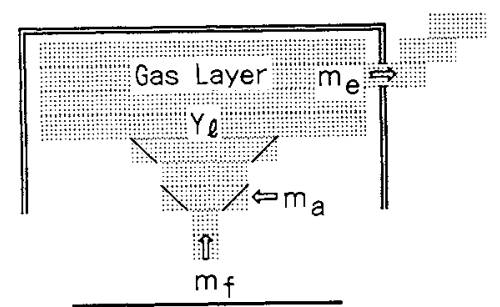


b) when $\Phi>1$ (fuel rich case)

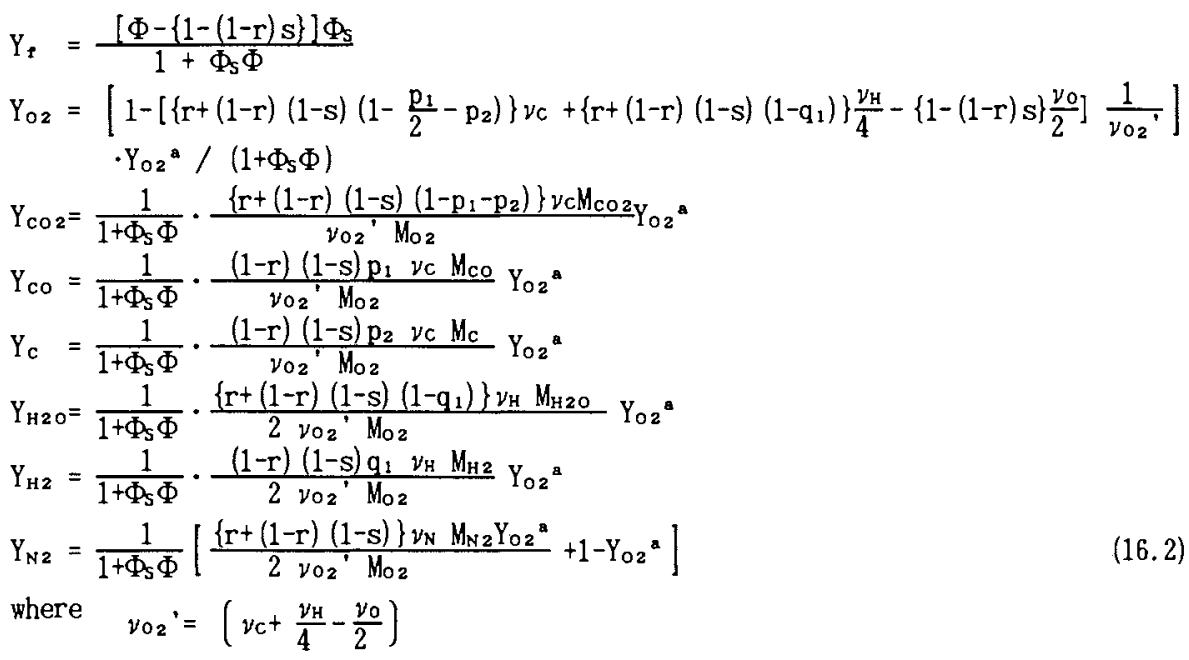

\section{ASSUMPTION FOR NORMALIZED YIELDS}

Beyler [2] conducted experiments for five types of hydrocarbon $\left(\mathrm{C}_{3} \mathrm{H}_{8}, \mathrm{C}_{3} \mathrm{H}_{6}, \mathrm{C}_{6} \mathrm{H}_{14}\right.$, $\mathrm{C}_{7} \mathrm{H}_{8}$ and $\left.\mathrm{CH}_{4}\right)$, three types of alcohol $\left(\mathrm{CH}_{3} \mathrm{OH}, \mathrm{C}_{2} \mathrm{H}_{5} \mathrm{OH}\right.$ and $\left.\mathrm{C}_{3} \mathrm{H}_{7} \mathrm{OH}\right)$ and acetone $\left(\mathrm{C}_{3} \mathrm{H}_{6} \mathrm{O}\right)$ as fuels, and concluded that the normalized yield of $\mathrm{CO}$ as a function of equivalence ratio for all the fuels examined were qualitatively similar to that found with propane.

While his data indicate that yield of $\mathrm{C0}$ depend on chemical structure of fuel, the normalized yield of $\mathrm{CO}$ for propane seemed to be about the average of those fuels. In addition, the normalized yields of $\mathrm{C} 0$ of wood does not seem far different from that of propane as long as examining Tewarson's data. [6]

Hence, for the purpose of practical applications, we assume that the normalized yield of a species can be regarded as the same for all types of fuels. It follows that this assumption implies that the results previously obtained for propane can be used for any fuel.

It may be a rather bold assumption, however, at this moment there will be no other practical means to predict concentrations of species for realistic fuel in fire.

For propane, we[1] have found that the parameter values empirically determined as follows exhibit acceptable agreement with Beyler's data[2],
a) when $\Phi \leqq 1$
$r=1-\left(1-r_{0}\right)^{(1 / \Phi)^{2}}, r_{0}=0.75$
$s=0.4$
$\mathrm{p}_{1}=0.6$
$\mathrm{p}_{\mathbf{2}}=0.1$
$\mathrm{q}_{1}=0.25$

b) when $\Phi>1$

$$
\begin{array}{lll}
r=0.75 & & \\
\mathrm{~s}=1-\left(1-\mathrm{So}_{0}\right) & (1 / \Phi)^{2} & , \text { so }=0.4 \\
\mathrm{p}_{1}=\mathrm{p}_{10} \times \Phi^{1 / 2} & , \mathrm{p}_{10}=0.6 \\
\mathrm{p}_{2}=0.1 、 & & \\
\mathrm{q}_{1}=\mathrm{q}_{10} \times \Phi^{1 / 2} & , \mathrm{q}_{10}=0.25
\end{array}
$$

As we notice by Eqs. (11.1), (11.2), (17.1) and (17.2), the normalized yield of each species is, except oxygen, only a function of equivalence ratio and parameters $r$, $s, p_{1}, p_{2}$ and $q_{1}$, so it follows from the above assumption that these parameters are the same regardless the fuel type, so those for propane can be used for any fuel. 


\section{PREDICTED RESULTS IN STEADY STATE}

\subsection{Comparisons of Concentration of Species between Prediction and Experiment}

Figure 3 exhibits the comparisons of the predicted layer species concentrations in volume fraction with the experimental data for propylene, and Figure 4 exhibits those in mass fraction for natural gas, respectively. The data in Figure 3 are from Morehart [3] and Beyler [7], and the data in Figure 4 are from Morehart [3] and Toner [8]. The fuel data for methane were used in the prediction of natural gas, since natural gas mainly consists of methane.

In Figure 3 and 4, fair agreement is exhibited between the predictions and the
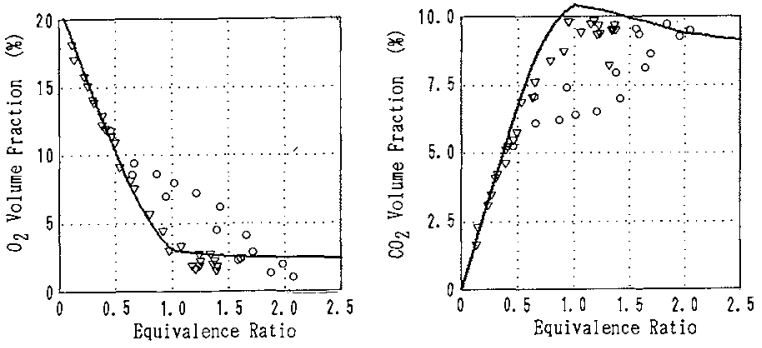

FIGURE 3. Comparisons of layer volume fraction between prediction and experiment for propylene $\left(\mathrm{C}_{3} \mathrm{H}_{6}\right)$ (solid line : prediction ( : Mor ehart [3], $\nabla:$ Beyler [7]
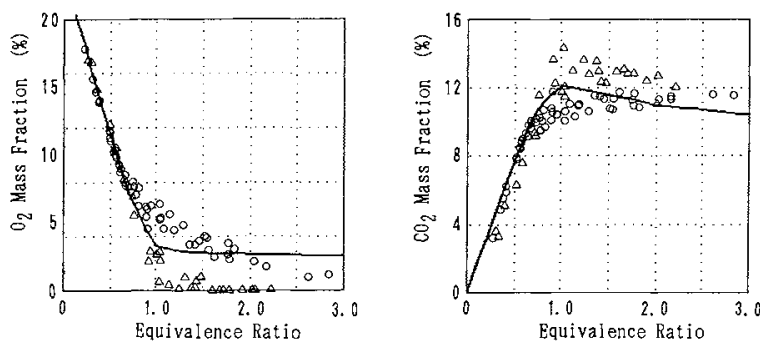

FIGURE 4. Comparisons of layer mass fraction between prediction and experiment for natural gas $\left(\begin{array}{l}\text { solid line : prediction } \\ O: \text { Morehart [3], } \triangle: \text { Toner [8] }\end{array}\right)$
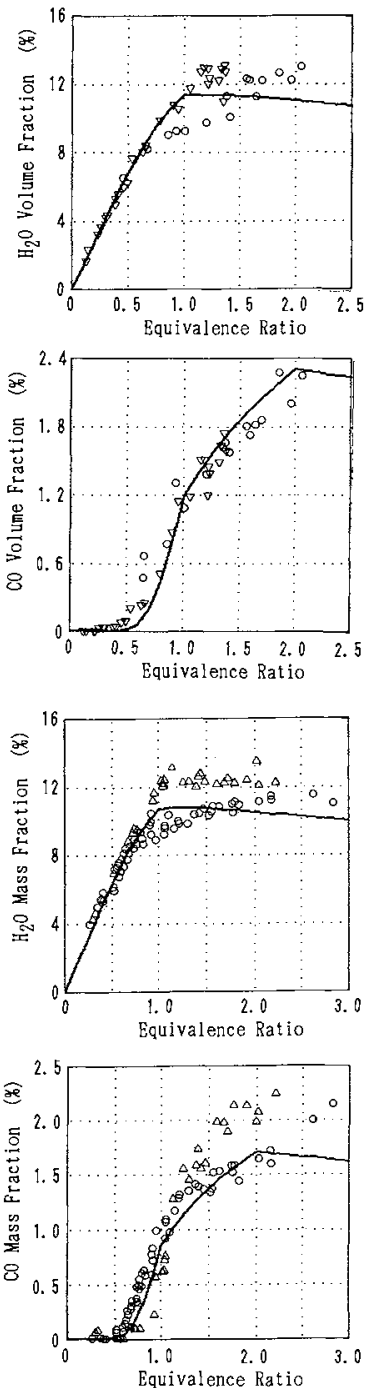
experimental data for every product species. Although in Figure 3, significant difference is observed between Morehart's data and the predicted concentrations of $\mathrm{O}_{2}$ and $\mathrm{CO}_{2}$ for $0.5<\Phi<1.5$, and in Figure 4 , some difference is observed between Toner's data and the predictions of $0_{2}$ and $\mathrm{CO}$ for $\Phi>1.5$.

In these figures, it is obvious that the data by Morehart for $\Phi>0.75$ are significantly different from those by Beyler and Toner. Morehart attributed this difference to the effect of the layer temperature caused by the different thermal properties of the test setups. Such temperature effect may be important in the species yields in fire, but at this stage we ignored this factor.

\subsection{Accuracy of The Species Yield Model}

The experimental data available for the purpose of evaluating the accuracy of the present species yield model have been limited to only three types of fuels: propane [1], propylene and methane. While further study might be necessary, the results for these fuels so far seem satisfactory.

Because all of these fuels are composed only of carbon and hydrogen and have mainly a single bond chemical structure, further experimental data will be necessary of the fuels containing oxygen and nitrogen, and having double bond structure. The mutual influence when multiple fuels exist should also be investigated. However, all of these complicated issues are ignored in this model, since they are beyond its capacity.

\section{EXTENSION OF THE MODEL TO TRANSIENT FIRE CONDITION}

The previous two layer zone model BRI2 can predict the concentration of $\mathrm{CO}$ in smoke layer only when the production rate at the source is specified. On the other hand, BRI2V, which is the revised version of BRI2 having incorporated the species yield model, can predict the $\mathrm{CO}$ production rate itself.

\section{1 Considerations}

Thanks to the elaborate experiments by Beyler, Morehart, Toner and others, the relationship of the species yields with equivalence ratio is quantitatively established for steady state fire scenario.

Our recognition is that this relationship is the only basis available at this moment for our attempt to develop a practical means to predict $\mathrm{CO}$ yield in fire.

In many practical issues concerning fire, it is important to predict $\mathrm{CO}$ concentration in transient state of fire. So the important issue is how we can apply the relationship established for steady state to transient state.

In such a period as the transient development of the upper layer, the relationship between equivalence ratio and concentration of each species established by steady state experiments will not hold, because the oxygen concentration in the layer does not correspond to the equivalence ratio. We may take into account the oxygen entrained into the plume in upper layer, but this will be too complicated to be practical.

Also we have to recognize that equivalence ratio may not be the direct governing factor of species yields, since the oxygen in the layer etc. changes corresponding to the equivalence ratio. It is not clear which is a dominant factor equivalence ratio or species concentration, in other words, the relationship between them is only empirical.

From the standpoint that we have to use the empirical relationship, it is the same thing whether we choose equivalence ratio or layer concentration, since one value of equivalence ratio corresponds to one value of the layer concentration. 


\subsection{Incorporation of the Species Yield Model into BRI2}

In the present species yield model, the rate of production of each species is given as a function of parameters $r, s, p_{1}, p_{2}$ and $q_{1}$. And each parameter is, in general, a function of equivalence ratio. Further more, as we have already seen, equivalence ratio can be said a function of layer concentration. So, it follows that the rate of production of each species is a function of the layer concentration.

For our purpose, layer concentration is much more convenient than equivalence ratio, since it is calculated for every time step in the zone fire model. The most convenient concentration to use is that of oxygen since, as we have seen in Figure 3 and 4 , this has a one-to-one correspondence to equivalence ratio.

The most important assumption in utilizing this species yield model into BRI2 is a quasi-steady state assumption, that is, the assumption that the empirical relationship between layer concentration and the rates of species production holds at every instant in transient change of fire.

The algorithm of calculating the rate of production of species is shown in Figure 5. The rates of species production at next time step is calculated using the oxygen concentration at current time step, and the concentration of oxygen and other species at next time step can be predicted with the calculated rates of species production.

\section{COMPARISONS BETWEEN PREDICTION AND EXPERIMENT}

\subsection{Experiments}

Small scale compartment fire experiments were conducted to obtain the data for $c 0$ concentration in transient period of fire for examining the validity of the model.

The compartment measuring $86 \mathrm{~cm} \times 86 \mathrm{~cm} \times 73 \mathrm{~cm}$ (height) which has an opening measuring $15 \mathrm{~cm} \times 15 \mathrm{~cm}$ in one of the wall, as shown in Figure 6 , is used as the fire room. The walls are made of perlite-board.

The fire source in each test is methanol pool in one of the circular steel pans with four different diameters : $15,20,25$ and $30 \mathrm{~cm}$. Methanol is used as the fuel to examine the applicability of the model to oxygen containing fuels. The burning

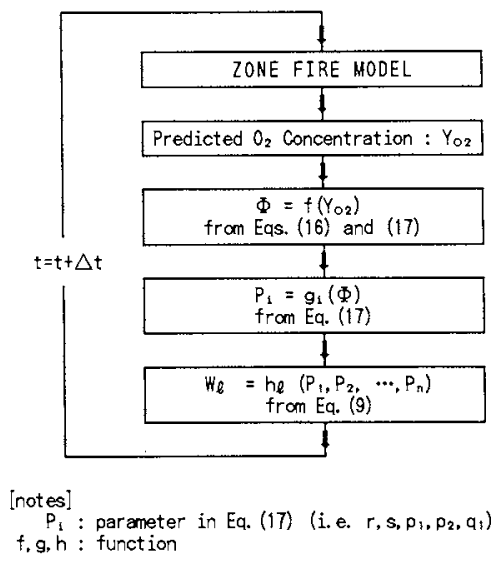

FIGURE 5. Algorithm of calculating the rate of production of species rate of methanol in each pan was measured in free space prior to the compartment fire tests, which are indicated in Table 1. Although the burning rates may change in the compartment, we could not succeed to make reliable weight loss measurements.

TABLE 1. Condition of experiments

\begin{tabular}{l|c|c|c|c}
\hline Exper iment No. & No.1 & No. 2 & No.3 & No.4 \\
\hline Fire room (cm) & \multicolumn{4}{|c}{$86 \times 86 \times 73^{\mathrm{H}}$} \\
\hline Opening (cm) & \multicolumn{4}{|c}{$15 \times 15^{\mathrm{H}}$} \\
\hline Diameter of & & & & \\
alcohol pan (cm) & 15 & 20 & 25 & 30 \\
\hline Burning rate (kM) & \multicolumn{5}{|c}{ (in free space) } \\
O 60 sec. & 5.6 & 10.6 & 15.0 & 19.8 \\
60 sec. & 8.3 & 12.9 & 19.6 & 26.0 \\
\hline
\end{tabular}



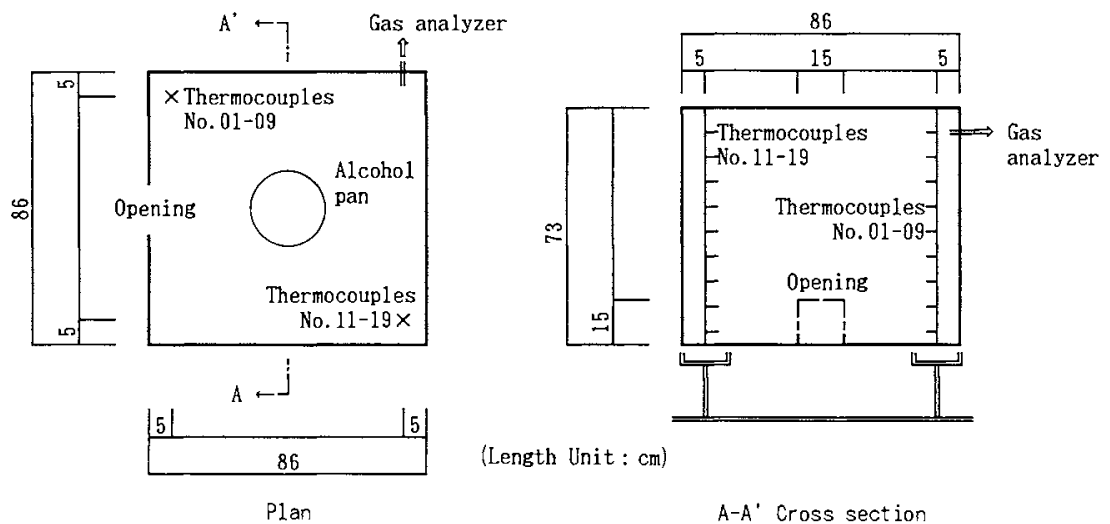

A-A' Cross section

FIGURE 6. Schematic of test compartment

\subsection{Prediction}

The conditions of the tests concerning the fire compartment and the fire source were inputted into BRI2V mode1, which is a modified version of BRI2 incorporating the species yield model.

The surface areas of fuel pan are inputted as the fire source area, although it was observed that flame did not cover all the surface of the pan under oxygen lean conditions. This may affect the prediction because the area is an important factor to govern the entrainment rate in near region of the source.

The following value are used as the convective heat transfer coefficient:

$\alpha_{c}(W / m / K)= \begin{cases}10 & (r 5300 K) \\ 0.04 T-2 & (300 K<T<800 K) \\ 30 & (800 \mathrm{~K} \leqq \mathrm{~T})\end{cases}$

where $T$ is the average temperature of the layer and the wall surfaces.

\section{3 Comparisons between The Predictions and The Experiments}

Comparisons for $\mathrm{O}_{2}, \mathrm{CO}_{2}$ and $\mathrm{CO}$ concentration are shown in Figure 7 . The direct goal of this study is to predict concentrations of species, but the layer temperature is always the most important item in the prediction of fire behavior, so comparisons for temperature are also shown in Figure 7.

(1) Concentrations of chemical species

The $\mathrm{O}_{2}, \mathrm{CO}_{2}$ and $\mathrm{CO}$ concentrations in the figures are the values after the $\mathrm{H}_{2} \mathrm{O}$ has been removed both in the tests and predictions. Predicted and experimental concentrations tend to agree fairly well. In experiment No. 1 and 3 , the predicted results are reasonable, however, some differences can been seen in experiment No. 2 after 600 seconds and in experiment No. 4 between 120 and 900 seconds.

(2) Temperature of the layer

As can be seen in these figures, general tendency of temperature curves is in fair agreement between the tests and the predictions, although, quantitatively, the predicted temperatures are slightly higher than those of the tests, despite the fact that the convective heat transfer coefficient is set at a larger value than that in the previous BRI2. 
A couple of causes are suspected for the difference : we could not succeed to make reliable measurements for the burning rates of fuel in the tests, so the input data for prediction may not have been so accurate, the convective heat transfer coefficient for such a small scale compartment may be different from that of full scale fire, and the wall thermal properties may not be the same between the predictions and the tests.
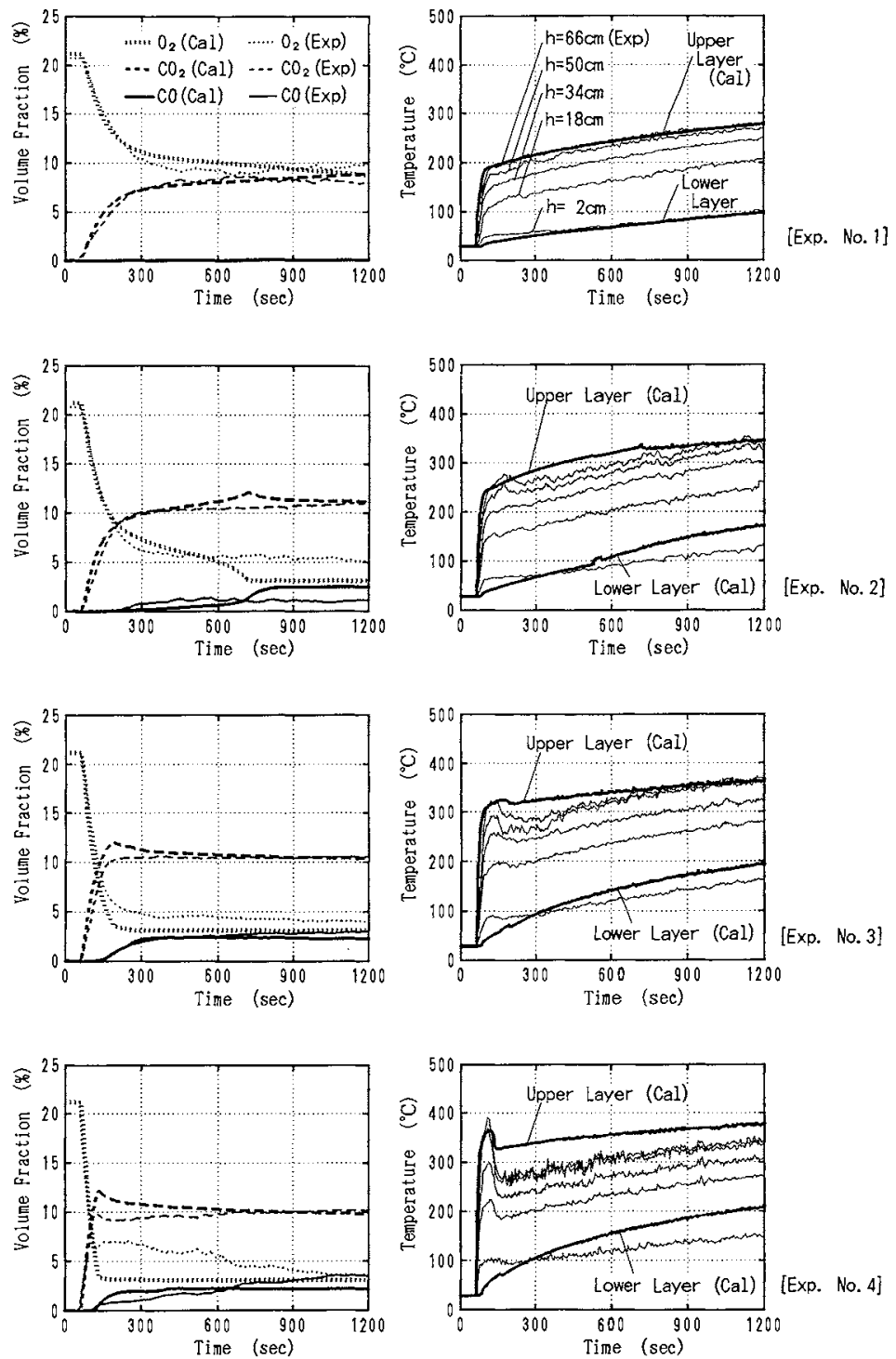

FIGURE 7. Comparisons of volume fraction and temperature between prediction and experiment 


\section{CONCLUDING REMARKS}

Some discrepancies between the predicted and experimental values still remain. In some other cases, the error is not reasonable, particularly in cases when oscillation behavior was observed in the tests. However, the tendency of the predicted and experimental values are similar, so this methodology seems to be a convenient and viable way of predicting carbon monoxide yields in transient state.

\section{NOMENCLATURE}

$$
\begin{aligned}
& \mathrm{m}_{\mathrm{b}}: \text { mass burning rate }(\mathrm{kg} / \mathrm{s}) \\
& \mathrm{m}_{\ell}: \text { mass rate of species } \ell(\mathrm{kg} / \mathrm{s}) \\
& \mathrm{M}_{\ell}: \text { molecular weight of species } \ell(\mathrm{kg} / \mathrm{mol}) \\
& \mathrm{T}: \text { temperature }(\mathrm{K}) \\
& \mathrm{W}_{\ell}: \text { the rate of production of species } \ell(\mathrm{kg} / \mathrm{s}) \\
& \bar{W}: \text { normalized yield of species } \ell \\
& \mathrm{X}_{\ell}: \text { mass fraction of element } \ell \text { in the fuel }(\mathrm{kg} / \mathrm{kg})
\end{aligned}
$$

$Y_{\ell^{\mathfrak{f}}}, Y_{\ell^{a}}, Y_{\ell}:$ mass fraction of species $\ell$ in fuel, air and in the laver, respectively $(\mathrm{kg} / \mathrm{kg})$

$\mathrm{Y}_{\mathrm{O} 2}{ }^{\mathrm{a}}$ : mass fraction of oxygen in the air $(\mathrm{kg} / \mathrm{kg})$

$\Phi$ : equivalence ratio, normalized fuel/air ratio

$\Phi_{\mathrm{s}}:$ stoichiometric fuel/air ratio

$\alpha_{c}:$ convective heat transfer coefficient $(\mathrm{W} / \mathrm{m} / \mathrm{K})$

$\nu_{\ell}$ : mole number of element $\ell$ in unit mass of the volatile leaving the fuel $(\mathrm{mol} / \mathrm{kg})$

$\nu \ell^{\prime}:$ stoichiometric coefficient of species $\ell$ in reactant system

$\nu \ell^{\prime \prime}:$ stoichiometric coefficient of species $\ell$ in product system

\section{REFERENCES}

1) Tanaka.T, Yamada.S : An Empirical Model of the Yield of Carbon Monoxide in Fires, Fire Science and Technology (Submitted)

2) Beyler.C.L ; Major Species Production by Diffusion Flames in a Two-layer Compartment Fire Environment, Fire Safety Journal, 10, pp.47- 56, 1986

3) Morehart.J.H, Zukoski.E.E, Kubota. T : Species Produced in Fires Burning in Two-Layered and Homogeneous Vitiated Environments, NIST-GCR-90-585, 1990.12

4) Forestry Experiment Station, Ministry of Agriculture and Forestry : Wood Industry Handbook, Maruzen (in Japanese)

5) Product Research Committee ; Materials Bank Compendium of Fire Property Data, PRC \& NBS, 1980

6) Tewarson.A : Correlation for the Generation of Carbon Monoxide in Sma11-and Large-scale Fires, 9th Meeting of the UJNR Panel on Fire Research and Safety, pp. 267-278, 1987.5

7) Beyler.C.L ; Development and Burning of a Layer of Products of Incomplete Combustion Generated by a Buoyant Diffusion Flame, Ph.D.Thesis, Harvard University, Cambridge, MA., 1983

8) Toner.S.J : Entrainment, Chemistry and Structure of Fire Plumes, Ph.D. Thesis, California Institute of Technology, Pasadena, CA, 1986

9) Tanaka.T : A Model on Fire Spread in Small Scale Buildings, 2nd Report, BRI Research paper No. 84, 1980.5 